\title{
Assessment of Anxiety and Depression among Drug Addicts at the Addiction Management Unit of Assiut University Hospital
}

\author{
Shymaa Mohammed Sayed, Ikram Ibraheem Mohamed \& Hossam Eddin Khalifa Ahmad \\ Demonstrator of Psychiatric Nursing, Faculty of Nursing, Assiut University, Egypt. \\ Professor of Psychiatric Nursing, Faculty of Nursing, Assiut University, Egypt. \\ Assistant professor of psychiatry, Faculty of medicine, Assiut University, Egypt.
}

\begin{abstract}
Addiction is a social, health, economic and cultural harm and problem that have influenced the future sovereignty and security of countries. The interactions between anxiety, depression and drug addiction are complex, approximately $31 \%$ of depression and anxiety has been found among drug addict people in Egypt. Aim of the study: To assess levels of anxiety and depression, and assess the difference between levels of anxiety and depression among drug addict people. Subjects and method: Non experimental (case-control) research design used to conduct this study. The current study included 150 subjects, 100 were drug addict people \& 50 were drug non- addict people. Tools of study included demographic and clinical data sheet, Drug Use Disorder Identification Test, Hamilton Anxiety Rating Scale, and Hamilton Depression Rating Scale Results: The majority of drug addict people had severe levels of anxiety and depression as compared to normal non- addict people. Using patterns and various drug related problems was positively and significantly correlated with anxiety $(r=0.256 \& p=0.010 *)$ and depression $(\mathrm{r}=0.330 \& \mathrm{p}=0.001 * *)$. The present study can concluded that drug addict people had severe levels of anxiety and depression than drug non-addict people Recommendations: psychosocial counseling program for drug addict people to decrease depression and anxiety.
\end{abstract}

Keywords: Anxiety, Depression, Drug Addict People.

\section{Introduction}

Addiction is a chronic, relapsing brain disease that is characterized by compulsive drug seeking and use, despite harmful consequences. It is considered a brain disease because drugs change the brain change its structure and how it works. These brain changes can be long lasting and can lead to many harmful, often selfdestructive, behaviors (Washington, 2011). According to the American Medical Association (2015); reported that, $50 \%$ of individuals with severe mental disorders are affected by substance abuse. As well $37 \%$ of alcohol abusers and $53 \%$ of drug abusers also have at least one serious mental illness. Of all people diagnosed as mentally ill, $29 \%$ abuse either alcohol or drugs.

Drug addiction has reached epidemic levels across the globe. There are 230 million drug users worldwide. The National Survey on Drug Use and Health was reported that 23.9 million American citizens over age 11 had used illicit drugs in the month preceding the survey, with

only 2.6 million seeking the help they need to reach recovery (Winstock, 2014). In this respect, United Nations statistics (2013) reported that there are 28 million drug users in Africa and about 37,000 people in Africa die annually from diseases associated with the consumption of illegal drugs. In Cairo drug addiction is becoming a major problem. The latest drug abuse report produced by the Ministry of Health and population recorded drug addiction in Cairo to be at record high levels, with 5 to $7 \%$ of the population to be addict to some form of drugs. With 5 to $7 \%$ are abusing drugs harmfully and are dependent, which is incredibly high. Data samples came from Helwan, Heliopolis, Manshiyet Nasser, Old Cairo and Shubra, to name only a few. Of those surveyed, just over $30 \%$ said they were substance users. Out of the substance users, about $90 \%$ used hashish, $35 \%$ drank alcohol, $32 \%$ used opiates, $27 \%$ used pharmaceutical drugs, $25 \%$ used other substances like solvents and inhalants, and $3 \%$ used cocaine and amphetamines (Steven, 2015).

Drug addiction, anxiety and depression account for three quarters of the disability attributed to mental disorders. Depression and anxiety symptoms are among the most common problems reported by persons seeking treatment for drug addiction (Begg et al., 2007).

Johnson, (2011) reported that, anxiety can be caused by drug addiction. Drug addiction increases anxiety in some individuals. Anxiety commonly occurs during the acute withdrawal phase of alcohol and can persist for up to 2 
years as part of a post-acute withdrawal syndrome, in about a quarter of people recovering from alcoholism.

Similarly, Conway et al., (2007) reported that, anxiety is common during withdrawal from drug addiction, and symptoms associated with drug addiction and withdrawal can simulate most anxiety. Approximately $17.7 \%$ of respondents with drug addiction in the past 12 months also met criteria for anxiety, and $15 \%$ of those with any anxiety in the past 12 months had at least one co-occurring drug addiction. Relationship between anxiety and drug addiction was stronger than the relationship between anxiety and alcohol abuse.

Watson, (2012) reported that, a person who has a drug or alcohol addiction problem may develop anxiety issues as a result of their dependence. Drugs or alcohol alter the functioning of the brain by either exciting or inhibiting certain neurotransmitters responsible for pain, emotion, hunger and fatigue. Long term drug use can damage the brain's ability to function normally and anxiety can arise. In order to prevent this from happening, a person may need to utilize a dual diagnosis rehab center for anxiety and drug addiction.

On the other hand, Compton et al., (2007) reported that, individuals with drug addiction frequently suffer from depression that is usually associated with poorer treatment outcomes, increased morbidity and mortality and higher treatment cost. In this respect, Najt et al., (2011) reported that, depression and drug addictions are critical, not only because of their high prevalence but also because of their negative consequences. Individuals with comorbid mental health problem and drug addiction often experience severe illness, disability and poor treatment outcomes.

Comer \& Ronald (2014) stated that, depressive symptoms may develop, as a direct result of taking drugs or as part of withdrawal symptoms when drug-taking stops. Low mood in withdrawal may be brief and self-limiting, but sometimes it can lead to serious, prolonged depressive symptoms. A person may take drugs to 'escape' from a problem during a particularly stressful time in their life. This stress may also be the trigger for an episode of depression. Heavy drug use can lead to major financial problems, difficulties with relationships or trouble with the law. A person taking recreational drugs is likely to have more of these pressures, which may trigger depression.
Philo, (2014) stated that, nurses working in a drug addiction unit are often charged with monitoring the detoxification of patients who are admitted. They play a teaching role in providing physical care. They teach patients about the dangers of drug abuse and withdrawal symptoms, including the physical and psychological effects (such as anxiety and depression) and the impact on meeting basic needs. So nurses must assess patient for signs and symptoms of anxiety (e.g. verbalization of feeling anxious, insomnia, restlessness, tachycardia, elevated blood pressure, selffocused behaviors).

In addition, nurses must assess patient for signs and symptoms of depression (e.g. feeling of sadness, helplessness, hopelessness, worthlessness, low self-esteem, change in sleep, and change in appetite). Nurses must convey acceptance to the patient and spend time with the patient when the patient not speaks and set with the patient in silence for short period. Nurses must provide close observation as indicated to ensure the patient's safety and provide a quiet and calm environment (Nadine, 2013).

\section{Significance of the study}

A high prevalence of depression and anxiety has been found

among drug addict people in high-income country settings using different diagnostic methods, instruments, cut-off values and population samples. Approximately $31 \%$ of depression and anxiety has been found among drug addict people in Egypt (El-sawy et al., 2011). In this respect, Darweesh \& Mohamed, (2008) reported that, approximately $7 \%$ of anxiety and $16 \%$ of depression has been found among drug addict people in Assiut. A number of studies have indicated that anxiety and depression among drug addict people have to worse prognoses, including a decreased rate of remission, an increased rate of relapse, and a need for more treatment services (Weisner et al., 2006). So, the present study could be helpful in gaining information that accurately assists in the management of drug addict people regarding their psychological problems (i.e.) their depression and anxiety.

\footnotetext{
Aim of the study

Assess levels of anxiety and depression among drug addict people.

Assess the difference between levels of anxiety and depression among drug addict people.
} 


\section{Research questions}

- Are drug addict people suffering from anxiety and depression?

- Is there a difference between levels of anxiety and depression among drug addict people?

\section{Subjects \& Method \\ Research Design}

Non experimental (case- control) design was utilized to conduct this study.

\section{Setting}

The study was conducted at inpatient unit of addiction management at Assiut University Hospital. Assiut University Hospital is the biggest hospital in Upper Egypt provides health services for Assiut city and most of the neighboring governorates. The inpatient of addiction management unit for management of drug addiction disorders includes 8 rooms, each room 2 beds and 1 bathroom. Nurses' number is 8 nurses. The monthly average patients' number is 40 and reaches approximately 500 per year from admission office at Assiut University Hospital from December 2015 to end May 2016.

\section{Sample}

A sample of one hundred (100) drug addict people and fifty (50) drug non- addict people were selected from employee worked at Assiut University Hospital, students studied in faculty of nursing and relatives of patients in Assiut University Hospital according to the following criteria.

\section{Criteria of selection}

- Inclusion Criteria for drug addict people

- Diagnosed with drug addiction only.

- Age ranged between (15 to 55 years).

- Accept to participate in the study.

Exclusion Criteria for drug addict people

- Drug addict people with mental retardation.

- Drug addict people with organic brain disorder.

- Other co-morbid psychiatric disorders.

Inclusion Criteria for drug non- addict people

- Not history of drug addiction.

- Age ranged between (15 to 55 years).

- Free from chronic medical conditions such as (cancer, renal failure or heart diseases). What about other disease (liver, arthritis, diabetes, asthma, cerebral disease).

- Accept to participate in the study.

Exclusion Criteria for drug non- addict people

Presence of co-morbid psychiatric disorders.

Tools of the study The following tools were used in this study

Tool (1): Socio demographic and clinical data sheet

Such as code No, age, gender, marital status, residence, occupation and level of education ....et and clinical data as diagnosis, types of drugs use, methods of drug used, history of drug used and causes of drug use.

Tool (2): Drug Use Disorder Identification Test (DUDIT) (Arabic version by Anis, 2014).

This scale has been developed in the original English language version by Berman et al; (2002) and translated into Arabic version by Anis, (2014).The purpose of Drug Use Disorder Identification Test was to identify use patterns and various drug-related problems. It consists of 11 -item, the first 9 items with five response alternatives each were coded as $0=($ never $), 1=($ once $/$ month or less over $), 2=(2-4$ times / month)

$3=(2-3$ times a week $), 4=(4$ times a week or more often).

While, items 10 and 11 had only three response alternatives were coded as

$0=($ no), $2=($ yes but not over the past year), $4=($ yes over the past year).

The total score of this test was 44 points. A Patient with 6 points or more probably has drug-related problems (for example, risky or harmful drug habits that might be diagnosed as substance abuse/harmful use or dependence while, Patient with 25 points or more is probably heavily dependent on drugs).

The scale was reported to have moderate reliability using Cronbach's Alpha (0.780), and possesses high validity using Pearson correlation, $(\mathrm{r}=88 \%)$ for the total scale.

Tool (3): Hamilton Anxiety Rating Scale (HAM-A) This Scale has been developed by Hamilton, (1959) and was translated into Arabic language by Fateem, (1994) and back translated into English to check translation validity and was later updated by Bech, (2011). The purpose of this scale was to measure the severity of anxiety. The Hamilton Anxiety Rating Scale consists of 14 -items, each item was scored based on a five-point; liket scale ranging from (0) $=$ Not Present, to (4) $=$ Very Severe.

The total score of this scale ranged from 0 to 56 , and was divided into four levels A score of 17 or less indicated mild anxiety, a score from 18 to 24 indicated mild to moderate anxiety; a score of 25 to 29 indicated a moderate to severe anxiety, a score more than 30 indicated severe anxiety.

The scale was reported to have high reliability by using Cronbach's Alpha (0.97) and possesses high validity by using Pearson correlation. $(\mathrm{r}=98 \%)$ for the total scale.

Tool (4):Hamilton Depression Rating Scale (HRS-D) This Scale has been developed by Hedlund, (1997) and was translated into Arabic language by

El-mistkawy, (2004) and back translated into English to check its translation validity \& was later updated by steve, (2010).The Hamilton Depression 
Rating Scale consists of 21 items to rate the severity of depression.

- Mild depression is ranging from 13 to 16.

- Moderate depression is ranging from 17 to 19.

- Severe depression is ranging from 20 to above.

The scale was reported to have high reliability using Cronbach's Alpha (0.94) and possesses high validity using Pearson correlation $(r=97 \%)$ for the total scale.

\section{Procedure}

After appraisal of the protocol of the study by ethical and scientific committee an official letter from the Dean of the faculty of Nursing Assiut University directed to the Head of the Neurology and Psychiatric medicine department at Assiut University hospital was included to get permission to conduct the study.

- Non experimental (case- control) research method was used to conduct the study.

- A pilot study was conducted on 20 drug addict people and 10 drug non- addict people of the sample. The purpose of the pilot study was to detect any particular problem in the statements clarity, feasibility, and applicability of the tools. No change was done in the assessment tools, so drug addict people and drug non- addict people selected for the pilot study were included in the main study.

- The aim of the study was explained to drug addict people and drug non- addict people before starting data collection.

- Application of the tools of the study took about from 45 - 60 minutes.

- Each participant was interviewed and assessed individually.

- The data collection took a period of six months, from December 2015 to the end of May 2016.

- Ethical consideration:-

- -Risk-benefit assessment: There is no risk during application of the research.

- Data Confidentiality and privacy was maintained during the research process.

- Informed oral consent to participate in this study was taken from all study subjects.

\section{Statistical design}

The data were tested for normality using the Anderson-Darling test and for homogeneity variances prior to further statistical analysis. Categorical variables were described by number and percent $(\mathrm{N}$, $\%$ ), where continuous variables described by mean and standard deviation (Mean, SD). Chi-square test was used to compare between categorical variables, where t-test was used to compare between continuous variables. Values at $\mathrm{p}<0.05$ were considered statistically significant. All analyses were performed with the IBM SPSS 20.0 software. 
Table (1): Comparison between drug addict $(n o=100)$ and drug non-addict people (no=50) regarding sociodemographic data.

\begin{tabular}{|c|c|c|c|c|c|}
\hline \multirow[t]{2}{*}{ Variables } & \multicolumn{2}{|c|}{$\begin{array}{c}\text { Drug addict people } \\
(\text { no=100) }\end{array}$} & \multicolumn{2}{|c|}{$\begin{array}{c}\text { Drug non- addict } \\
\text { people }(\text { no=50) }\end{array}$} & \multirow{2}{*}{$\begin{array}{l}\text { Test of sig } \\
\text { P. value }\end{array}$} \\
\hline & No. & $\%$ & No. & $\%$ & \\
\hline \multicolumn{6}{|l|}{ Age groups } \\
\hline $16-20$ years & 10 & 10.0 & 7 & 14.0 & \multirow{4}{*}{0.056} \\
\hline $21-30$ years & 56 & 56.0 & 22 & 44.0 & \\
\hline $31-40$ years & 30 & 30.0 & 13 & 26.0 & \\
\hline $41-50$ years & 4 & 4.0 & 8 & 16.0 & \\
\hline Age, mean+SD & \multicolumn{2}{|c|}{$28.1 \pm 6.5$} & \multicolumn{2}{|c|}{$30.9 \pm 8.7$} & 0.061 \\
\hline \multicolumn{6}{|l|}{ Marital status } \\
\hline Single & 38 & 38.0 & 13 & 26.0 & \multirow{2}{*}{0.144} \\
\hline Married & 62 & 62.0 & 37 & 74.0 & \\
\hline \multicolumn{6}{|l|}{ Residence place } \\
\hline Rural & 73 & 73.0 & 39 & 78.0 & \multirow{2}{*}{0.507} \\
\hline Urban & 27 & 27.0 & 11 & 22.0 & \\
\hline \multicolumn{6}{|l|}{ Level of education } \\
\hline Illiterate & 2 & 2.0 & 0 & 0.0 & \multirow{6}{*}{$0.002 * *$} \\
\hline Read and write & 2 & 2.0 & 0 & 0.0 & \\
\hline Primary & 3 & 3.0 & 1 & 2.0 & \\
\hline Preparatory & 3 & 3.0 & 1 & 2.0 & \\
\hline Secondary & 67 & 67.0 & 19 & 38.0 & \\
\hline University & 23 & 23.0 & 29 & 58.0 & \\
\hline \multicolumn{6}{|l|}{ Occupation } \\
\hline Not work & 14 & 14.0 & 3 & 6.0 & \multirow{5}{*}{0.158} \\
\hline Employee & 20 & 20.0 & 17 & 34.0 & \\
\hline Farmer & 4 & 4.0 & 1 & 2.0 & \\
\hline Student & 10 & 10.0 & 8 & 16.0 & \\
\hline Manual workers & 52 & 52.0 & 21 & 42.0 & \\
\hline
\end{tabular}

** Statistically significant values $(\mathrm{p}<0.01)$

Table (2): Clinical data of the drug addict people $(n=100)$.

\begin{tabular}{|c|c|c|}
\hline & N. & $\%$ \\
\hline \multicolumn{3}{|l|}{ Diagnosis } \\
\hline Poly drug addict & 83 & 83.0 \\
\hline Non-Poly drug addict & 17 & 17.0 \\
\hline \multicolumn{3}{|l|}{ Types of drug use } \\
\hline Tamol or tramadol & 17 & 17.0 \\
\hline Mixed (Tamol- Hashish- Opium- Banjo- Calmepam- Heroin- Nalufin) & 83 & 83.0 \\
\hline \multicolumn{3}{|l|}{ Methods of drug use } \\
\hline Oral & 68 & 68.0 \\
\hline Mixed (oral- inhalation- injection) & 32 & 32.0 \\
\hline \multicolumn{3}{|l|}{ History of drug used } \\
\hline Less than six month & 3 & 3.0 \\
\hline six month to one year & 4 & 4.0 \\
\hline More than one year & 93 & 93.0 \\
\hline \multicolumn{3}{|l|}{ Causes of drug use } \\
\hline Bad friends & 12 & 12.0 \\
\hline To give the patient strength and activity & 12 & 12.0 \\
\hline
\end{tabular}


To forget problems and feel flatten

Mixed (Bad friends, Trial, To give the patient strength and activity, To forget problems and feel flatten, Weakness of sexual ability, Excessive money, Chronic pain)

Table (3): Distribution of using patterns and various drug related problems among drug addict people $(n=100)$. Results of DUDIT

\begin{tabular}{|l|c|c|c|c|c|}
\hline \multicolumn{1}{|c|}{ Variables } & N. & \% & Min & Max & Mean \pm SD \\
\hline Drug related problems & 5 & 5.0 & 18 & 24 & $22.20 \pm 2.49$ \\
\hline Heavily dependent on drug & 95 & 95.0 & 26 & 38 & $31.45 \pm 2.47$ \\
\hline Total & 100 & 100.0 & 18 & 38 & $30.99 \pm 3.18$ \\
\hline
\end{tabular}

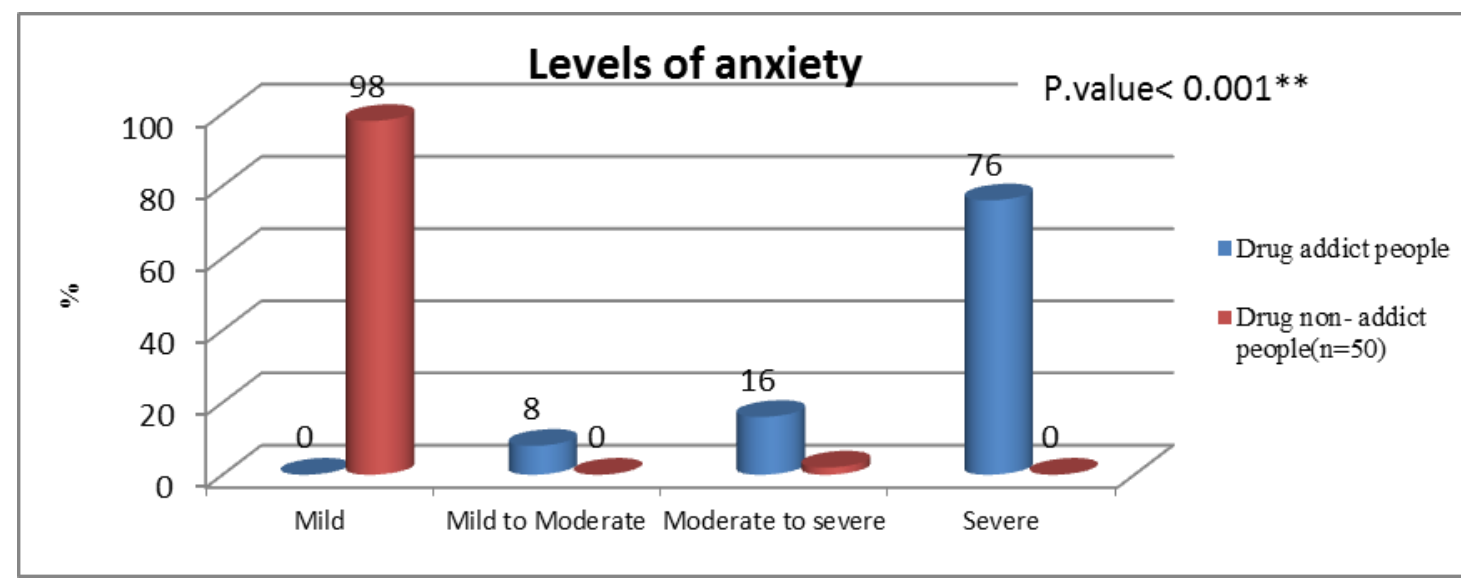

Figure (1): Comparison between drug addict $(n=100)$ and drug non-addict people $(n=50)$ regarding anxiety levels.

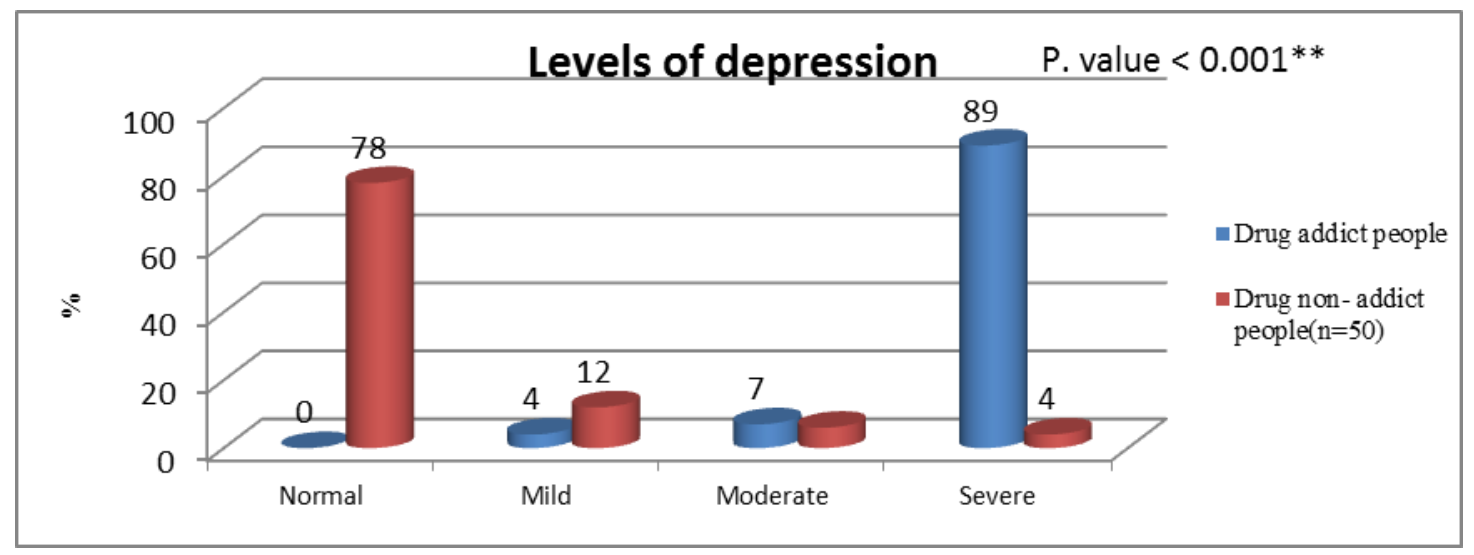

Figure (2): Comparison between drug addict $(\mathrm{n}=100)$ and drug non-addict people $(\mathrm{n}=50)$ regarding depression levels. 
Table (4): Correlation between using patterns and various drug related problems, anxiety and depression among drug addict people $(n=100)$.

\begin{tabular}{|l|c|c|c|c|}
\hline \multicolumn{1}{|c|}{ Variables } & & $\begin{array}{c}\text { Using patterns } \\
\text { and various drug } \\
\text { related problems }\end{array}$ & Anxiety & Depression \\
\hline \multirow{2}{*}{$\begin{array}{l}\text { Using patterns and various } \\
\text { drug related problems }\end{array}$} & $\mathbf{r}$ & 1 & & \\
\hline \multirow{2}{*}{ Anxiety } & $\mathbf{p}$ value & & & \\
\hline \multirow{2}{*}{ Depression } & $\mathbf{r}$ & 0.256 & 1 & \\
\cline { 2 - 5 } & $\mathbf{p .}$ value & $0.010^{*}$ & & 1 \\
\cline { 2 - 5 } & $\mathbf{r}$ & 0.330 & 0.630 & \\
\hline
\end{tabular}

* Statistically significant values $(p<0.05)$

$* *$ Statistically significant values $(p<0.01)$

Table (1): Presents a comparison between drug addict and drug non-addict people regarding them socio-demographic data. the mean age of drug addict people was $28.1 \pm 6.5,62 \%$ of them were married, $73 \%$ from rural area, $67 \%$ graduated from secondary schools, 52\% of them were manual workers. As regarding drug nonaddict people, their mean age was $30.9 \pm 8.7$, $74 \%$ of them were married, $78 \%$ were from rural area, $58 \%$ graduated from university education, $42 \%$ of them were manual workers. There were no significant differences between drug addict and drug non- addict people regarding socio- demographic data except for level of education where non- addict tend to be more educated $(\mathrm{p}=0.002 * *)$.

Table (2): shows the clinical characteristics of the drug addict people which indicated that, the majority of the drug addict people (83\%) were poly drug addict, who used mixed types of change as (Tamol- Hashish- Opium- BanjoCalmepam- Heroin- Nalufin), while $17 \%$ of them used tamol or tramadol. Regarding methods of drug use, $68 \%$ used drug orally, while $32 \%$ used mixed methods (oralinhalation- injection). Regarding history of drug use; $93 \%$ of the drug addict people used drugs for more than one year, $67 \%$ of many causes for using drugs as (bad friends, trial, to feel and be more active, to forget problems and feel flatten, to overcome weakness of sexual ability, having excessive money, to combat chronic pain). However, $12 \%$ of them reported that they used drugs because of bad friends and to gain more strength and activity respectively, while $9 \%$ of them reported that they used drugs to forget problems and feel flatten.

Table (3): shows using patterns and various drug related problems among drug addict people. It was revealed that $95 \%$ of drug addict people were heavily dependent on drug, with a mean score of $31.45 \pm 2.47$, while $5 \%$ are having drug related to problems, with a mean score of $22.20 \pm 2.49$.

Figure (1) Reveals a comparison between drug addict and drug non-addict people regarding their anxiety levels. This figure illustrated that, $76 \%$ of drug addict people had severe levels of anxiety while $98 \%$ of drug non-addict people had mild level of anxiety. There were statistically significant difference between drug addict and drug non-addict people regarding their levels of anxiety at $(\mathrm{p}<0.001)$.

Figure (2): demonstrats a comparison between drug addict and drug non-addict people regarding their depression levels which revealed that, $89 \%$ of drug addict people had severe levels of depression, while $78 \%$ of drug nonaddict people had no depression. There were statistically significant differences between drug addict and drug non-addict people regarding their levels of depression $(\mathrm{p}<0.001)$.

Table (4): shows that, using patterns and various drug related problems were positively and significantly correlated with anxiety $(\mathrm{r}=0.256 \& \quad \mathrm{p}=0.010) \quad$ and depression $(\mathrm{r}=0.330 \& \mathrm{p}=0.001)$. In addition, it was found that, anxiety was positively and significantly correlated with depression $(r=0.630 \& p=0.001)$.

\section{Discussion}

Addiction is a phenomenon that has long existed in human societies. Scientific advances and increased public awareness still expanding and every year many people take their livestock. Addiction is not just an individual aspect, but it is a social harm and the threat of physical and mental health. It also has irreversible effects on social and economic aspects of the society. All of the chemicals ingredients are that cause changes in brain functions in the form of excitement, anxiety and / or depression as in the 
addictive substances (Atashpour \& Sharifi, 2012).

The current study aimed to assess levels of anxiety and depression, and assess the difference between levels of anxiety and depression among drug addict people.

The current study revealed that, about more than two thirds of drug addict people had severe level of anxiety, while, the majority of drug non-addict people had mild level of anxiety. This could be explained by that anxiety commonly presented as a symptom of drug withdrawal, initially in the form of 'shakes and sweats' after the drug levels decreased. Also, long term drug use can damage the brain's ability to function normally and anxiety can arise.

These findings were similar to Hodgson et al, (2016) who showed that, more than two thirds of drug addict people had severe level of anxiety. While, the majority of drug non-addict people had mild level of anxiety. In contrast, these findings were incongruent with Liao et al, (2011) who found that, less than half of drug addict people had moderate to severe level of anxiety. While, one quarter of drug non-addict people had mild level of anxiety. This could be related to using different tools and different perspectives of the study.

The present study showed that, about the most of the drug addict people had severe levels of depression. While, more than two thirds of drug non-addict people had normal level of depression. This could be explained by that depression seemed to be one of the most common symptoms which experienced by the patients when they're recovering from drug addiction. Also, drugs alter the functioning of the brain by either exciting or inhibiting certain neurotransmitters which are responsible for emotion and causes depressive symptoms.

These results were consistent with finding of Pakhtunkhwa et al., (2012) who demonstrated that, about most of the drug addict people had severe levels of depression, while, more than two thirds of drug non-addict people had normal level of depression. Whereas, these findings were in contrary with Zhangy et al, (2012) who found that, slightly two thirds of drug addict people had moderate levels of depression. While, the most of drug non-addict people have normal level of depression.

The current study revealed that, using patterns and various drug related problems were positively and significantly correlated with anxiety and depression. This may be due to that drug addiction can damage normal brain function, and change neurotransmitter that can lead to anxiety and depression and also, longterm drug addiction and acute drug withdrawal can cause anxiety and depression symptoms. On the other hand, people with anxiety and depression symptoms can use drugs as coping mechanisms to manage anxiety and depression.

These findings were supported by Gil-Rivas et al., (2009) who found that, using patterns and various drug related problems were positively and significantly correlated with anxiety and depression. In the same aspect, Ortiz Gomez et al., (2014) reported that, using patterns and various drugs related problems are positively and significantly correlated with depression. Whereas, these findings were incongruent with Wilkinson et al., (2016) who found that, using patterns and various drug related problems are positively and non- significantly correlated with depression.

The present study showed that anxiety was positively and significantly correlated with depression. This may be related to anxiety as a state of emotional disturbance caused by a chemical disturbance in the centers of emotion in the brain which is correlated with depression, which leads to similar symptoms such as mental distraction and inability to focus and hesitation in making decisions. Also, depression is the seventh and final stage in the development of anxiety, and that it is normal and expected to become anxious patients pessimistic and depressed with their sense of finite disability and inability to bear life (Nagy, 2011).

These findings were similar to previous study reported by Grant et al., (2016) who found that, anxiety was positively and significantly correlated with depression. Whereas, these findings were contradicted with Bellos et al., (2016) who found that, anxiety was positively and non-significantly correlated with depression.

\section{Conclusion}

Based on the result of present study it can be concluded that, the majority of drug addict people had severe levels of anxiety and depression as compared to normal non- addict people. In addition, using patterns and various drug related problems was positively and significantly correlated with anxiety and depression. 


\section{Recommendations}

Based on the current study findings, the following recommendations are suggested

- Designing and implementing a psychosocial counseling program for drug addict people to decrease their levels of anxiety and depression.

- Educational program should be planned to educate nursing staff about psychological problems related to drug addict people.

\section{References}

1. American Medical Association (2015): Substance Abuse and Mental Health, help guide.org; 22(1): 47-57.

2. Atashpoor, H., \& Sharifi, G., (2012): Fourth International Congress on Psychosomatic, Islamic Azad University of Khorasgan; 12, (2), Pp.144- 149.

3. Bech, P., (2011): Measuring States of Anxiety with Clinician-Rated and PatientRated Scales, Different Views of Anxiety Disorders; 5772/21246.

4. Begg, S., Barker, B., Stevenson, C., Stanley, L \& Lopez, A., (2007): The burden of disease and injury, in PHE 82. Canberra; 44-48.

5. Bellos, S., Skapinakis. P., Rai, D., Zitko, P., Araya, R., Lewis, G., \& Mavreas, V., (2016): Longitudinal association between different levels of alcohol consumption and a new onset of depression and generalized anxiety disorder, Results from an international study in primary care, Psychiatry research; 24,(3), Pp.30-34.

6. Berman, A., Bergman, H., Palmstierna, T., \& Schlyter, F., (2002): Evaluation of the Drug Use Disorders Identification Test (DUDIT) in Criminal Justice and Detoxification Settings and in a Swedish Population Sample. European Addiction Research; 8, (3), Pp. 29-30.

7. Comer, B., \& Ronald, J., (2014): Substance-Related Disorders. Depression symptoms, In Abnormal Psychology, New York, NY: Worth; 8, (2), Pp.278-298.

8. Compton, W., Thomas, Y., Stinson, F., Grant, B., (2007): Prevalence, correlates, disability, and co-morbidity of DSM-IV drug abuse and dependence in the United States: Results from the national epidemiologic survey on alcohol and related conditions; 64, (5), Pp.566-576.

9. Conway, K., Stinson, F., Grant, B., (2007): Lifetime co-morbidity of DSM-IV mood and anxiety disorders and specific drug use disorders: Results from the National
Epidemiologic Survey on Alcohol and Related j ournal of ClinicalPsychiatry Conditions; 67, (2), Pp.247-257.

10. Darweesh. M., \& Mohamed, A., (2008): Co-morbidity of Substance Dependence and other psychiatric Disorders, the Egyptian journal of Neurological, psychiatric and Neurosurgery; 12, (1), Pp.17-27.

11. El- mistkawy. A., (2004): Reliability and validity of Hamilton Rating scale for Depression.

12. El-sawy. H., Abdel Hay, M., Badawy. A., (2011): Gender Differences in Risks and Pattern of Drug Abuse in Egypt, Egypt $\mathbf{J}$ Neural Psychiatry Neurosurgery; 37, (7), Pp.415-416.

13. Gil-Rivas, V., Prause, J., \& Grella, C., (2009): Substance use after residential treatment among individuals with cooccurring disorders, the role of anxiety/depressive symptoms and trauma exposure, Psychology of Addictive Behaviors; 23,(2), Pp.303-309.

14. Grant, B., Saha, T., Ruan, W., Goldstein, R., Chou, S, Jung. J., \& Hasin, D., (2016): Epidemiology of DSM-5 drug use disorder, results from the National Epidemiologic Survey on Alcohol and Related ConditionsIII, JAMA psychiatry; 73,(1), Pp.39-47.

15. Hamilton, M., (1959): The assessment of anxiety states by rating. $\mathrm{Br} \mathrm{J}$ Med Psychos; 32, Pp.50-55.

16. Hedlund, J., \& Viewig, B., (1979): The Hamilton rating scale for depression, a comprehensive review, Journal of Operational Psychiatry; 2, (10), Pp.149-165.

17. Hodgson, K., Almasy, L., Knowles, M., Kent, W., Curran, E., Dyer, D., \& Krystal, H., (2016): Genome-wide significant loci for addiction and anxiety, European Psychiatry; 36, (1), Pp. 47-54.

18. Johnson, A., (2011): Addiction medicine, science and practice. New York: Springer; 5, (3), pp. 301-303.

19. Liao, Y., Tang, J., Liu, T., Chen, X., Liu, X., \& Hao, W., (2011): A Pilot Study of Life Events and Mood Disorders, SelfReport Survey in Chinese Heroin-Dependent Individuals, Am J Addict; 20, (4), Pp. 337342.

20. Nadine, R., (2013): Brief treatment strategies for depression among addiction, Drug and diseases, A device for the primary care, Journal of advanced Practice Nursing;15, (7), Pp. 140-155. 
21. Nagy, D., (2011): Relationship between anxiety and depression, anxiety and depression. journal of psychiatric nursing; 205, (313), Pp.187-190.

22. Najt, P., Fusar, P., Brambilla, P., (2011): Co-occurring mental and substance abuse disorders, a review on the potential predictors and clinical outcomes, Psychiatry Research; 186, (9), Pp. 159-164.

23. Ortíz-Gómez, D., López-Canul, B., \& Arankowsky-Sandoval, G., (2014): Factors associated with depression and suicide attempts in patients undergoing rehabilitation for substance abuse, Journal of affective disorders; 169, (6), Pp. 10-14.

24. Pakhtunkhwa, P., PakistanNaz, A, Khan, W., Hussain, M., Daraz, U., Khan, T., \& Khan, Q., (2012): The menace of opiate, The socio-psychological and physiological impacts of opiate on addicts in Khyber, African Journal of Pharmacy and Pharmacology; 6, (24), Pp.1753-1764.

25. Philo, A., (2014): Nurses roles on anxiety and drug addiction, Journal of Substance Abuse Treatment; 45, (4), Pp.235-245.

26.Steve, C., (2010): Serenity program, depression and feeling low, The Hamilton depression rating scale; 20, (3), Pp. 33-35.

27. Steven, V., (2015): A drug addiction rises in Cairo; experts offer recommendations, addiction, drug, mental health, psychiatric; 11, (2), Pp.82-100.

28. United Nation Statistics (2013): Illegal drug use on the rise in Africa, Drug abuse Africa, Illegal drugs and substance; 33, (4), Pp.164-170.

29. Washington, D., (2011): National Drug Intelligence Center, The Economic Impact of Illicit Drug Use on American Society, United States Department of Justice; 33, (5), Pp. $220-222$.

30. Watson. H., (2012): The Science of Addiction, Drugs, Brains, and Behavior, anxiety, Medline plus; 63, (3), Pp. 135-178.

31. Weisner, C., Thomas, R., \& Mertens, J., (2006): Short-term alcohol and drug treatment outcomes predict long-term outcome. Drug and Alcohol Dependence; 71, (2), Pp. 281-294.

32. Wilkinson, A., Halpern, T., \& Herring, A., (2016): Directions of the relationship between substance use and depressive symptoms from adolescence to young adulthood, Addictive behaviors; 60, (5), Pp. 64-70.
33. Winstock, A., (2014): "The global drug survey findings", global drug survey, a journal of drug addiction; 29, (4), Pp.176-189.

34. Zhang, Y., Lu, C., Zhang, J., Hu, L., \& Song, H., (2012): Gender differences in abusers of amphetamine-type stimulants and ketamine in southwestern China, Addict Behave; 38, (7), Pp. 1424-1430.

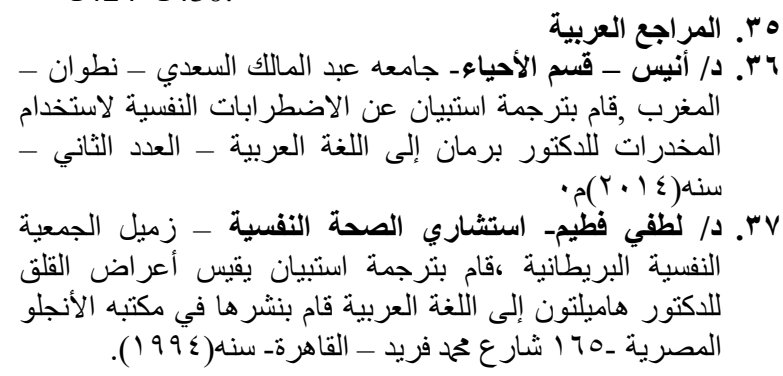

